\title{
Clinical Evaluation of Efficacy of Cyanoacrylate Glue and Conventional Polypropylene Suturing in Cutaneous Wounds-A Comparitive Study
}

\author{
Dr Yogitha Priyadarshini ${ }^{1}$, Dr (Col) Suresh Menon², Dr ME Sham ${ }^{3}$, Dr Veerendra ${ }^{4}$, Dr Archana $S^{5}$ and Dr \\ Alakananda $\mathbf{M}^{6 *}$
}

${ }^{1}$ MDS, Private Practitioner, Email: Yogitha.priyadarshini@gmail.com

${ }^{2}$ MDS, HOD, Professor, Email: psurmenon@gmail.com

${ }^{3}$ MD, MDS, MRM, PhD, Professor, Email: ehtaihsham@yahoo.com

${ }^{4}$ MDS, Assistant Professor, Email: drveeru07@gmail.com

${ }^{5}$ MDS, Senior Lecturer, Email: archana.dr.s@gmail.com

${ }^{6} \mathrm{MDS}$, Surgical resident,Email: alakananda.ms@gmail.com

*Corresponding author: Dr Alakananda Melethil, MDS, Surgical resident, India, Email: alakananda.ms@gmail.com

\section{Abstract}

Introduction: The benefits of assisting closure by holding the opposing edges of a wound together have been recognized in the last 5000 years. There are several well-proven techniques of skin closure using a variety of materials like braided or monofilament material, absorbable and nonabsorbable conventional suture materials, metal clips and adhesive tapes. Conventional skin suturing techniques do have certain disadvantages. From the past three decades, many new biomaterials have been discovered in the medical field. Bio-adhesives are one among them. These materials when applied on the incised tissues possess the ability to bind them together. This group of adhesives are called Cyanoacrylates. The purpose of the study was to compare the efficacy and clinical outcome of the two techniques of wound closure by using conventional polypropylene suturing and cyanoacrylate glue.

Objectives of the study: The objective of this study was to compare the pain, duration of the procedure, postoperative infection, wound dehiscence and esthetic outcome of cyanoacrylate with the polypropylene suturing in skin wounds.

Materials and method: A total number of 50 subjects, with lacerations of head and neck region in the age group of 15-40 years were included in the study. Group I: Lacerations closed using polypropylene Group II: Lacerations closed using cyanoacrylates Variables like pain, esthetic outcome, time taken, wound dehiscence, infection was taken into account.

Conclusion: In our study we noted that cyanoacrylates is an easily applied material, has good physical properties, has good wound healing characteristics, overcomes the disadvantage and discomfort of suture removal, infection, duration of closure and produces cosmesis comparable to that produced by sutures with excellent patient satisfaction. With a limited number of samples and study, we conclude that with a proper patient selection, meticulous technique and limitation to external use, Cyanoacrylate can serve as a good and reliable alternative to sutures for lacerated wounds in the minimal tension areas of the face.

\section{Introduction}

The benefits of assisting closure by holding the opposing edges of a wound together have been recognized since 5000 years. Initial treatment for wounds consisted of herbal balms or draughts with application of leaves or grass as bandages. The world's oldest suture was placed by the embalmer on the abdomen of a mummy in approximately 1100 BC. Only recently has wound care been systematically investigated both in the laboratory and in clinical arenas [1]. There are a number of well-proven techniques of skin closure using a variety of materials like braided or monofilament material, absorbable and non-absorbable conventional suture materials, metal clips and adhesive tapes. Conventional skin suturing techniques do have certain disadvantages. When tension upon the wound edges is too high, it produces prominent crosshatching along the scar and a poor cosmetic appearance. Metal clips produce excellent cosmetic results when they are removed within 48 or 72 hours, otherwise the local increased tension and ischemia 
produce ugly and permanent cross-hatching and a poor cosmetic appearance. Adhesive tapes designed to affect skin closure are mainly limited to small facial wounds on account of their size and adhesive property.

From the past three decades, many new biomaterials have been discovered in the medical field. Bio-adhesives are one among them. These materials when applied on the incised tissues possess the ability to bind them together. This group of adhesives are called Cyanoacrylates. Cyanoacrylates were first synthesized by Ardis in 1949 [2]. Cyanoacrylate derivatives are one of the series of homologous compounds known as alkyl cyanoacrylates. The adhesive property of cyanoacrylates is due to the fact that in monomer form, the cyanoacrylates are liquids and upon contact with weak bases and water they quickly form a strong polymer bond and solidify.

Coover, et al. [3] discovered the adhesive properties of cyanoacrylate adhesives and suggested their use as surgical adhesives. Methyl-2-cyanoacrylate (Eastman 910 monomer) was the first cyanoacrylate derivative packaged and marketed as a surgical adhesive. Longer chain derivatives such as ethyl-2cyanoacrylate (Krazy glue), isobutyl-2cyanoacrylate (Bucrylate) and butyl-2-cyanoacrylate (Histoacryl) have subsequently been developed [1]. Advantages of tissue adhesives over conventional wound closure techniques include ease of use, decreased need for local anesthesia, negligible tissue deformation and avoidance of needle stick injury. They also provide excellent waterproof wound protection, which act as a protective dressing, excellent bacteriostatic property, decreased repair time, elimination of recall visits and comparable short and long term cosmetic outcome. They are also found to provide good tensile strength and are safe with negligible histotoxicity upon application.

The first glue developed was Methyl Cyanoacrylate, which was studied extensively for its potential medical applications and was rejected due to its tissue toxicity. Methyl alcohol, which has a short molecular chain, contributes to this complication. Further research revealed that by changing the type of alcohol in the compound to one with a longer molecular chain, the tissue toxicity was reduced. By increasing the size of the molecule, it was possible to lengthen the time taken to polymerize [4]. N-butyl 2-cyanoacrylate is a commonly available medical grade tissue adhesive, which contains four alkyl groups in its side chain and which has been demonstrated to be an adhesive and hemostatic with bacteriostatic property. It is well tolerated by mammalian tissues and has been used as an adhesive in skin wounds. The purpose of the study was to compare the efficacy and clinical outcome of the two techniques of wound closure by using conventional polypropylene suturing and cyanoacrylate glue.

\section{Objectives of the Study}

The objective of this study was to compare the pain, duration of the procedure, post-operative infection, wound dehiscence and esthetic outcome of cyanoacrylate with the polypropylene suturing in skin wounds.

\section{Materials and Method}

Type of study: Prospective study

Study of Population: Patients reporting to the Department of Oral and Maxillofacial Surgery at Vydehi Institute of Dental Sciences and Research Centre, Whitefield, Bangalore.

\section{Methods of Collection of Data}

\section{Sample size}

A total number of 50 subjects, with lacerations of head and neck region in the age group of 15-40 years were included in the study. These subjects were randomly divided into two groups:

Group I: Lacerations closed using polypropylene.

Group II: Lacerations closed using cyanoacrylates.

\section{Inclusion criteria}

- Subjects requiring closure of the skin wounds in the head and neck region.

- Subjects between the ages of 15-40 yrs.

- Subjects with wounds less than 6hrs of duration.

- Subjects in good health (ASA classification 1 or 2).

- Subjects ready to sign informed consent.

- A clean, non-gaping and uncontaminated wound.

\section{Exclusion criteria}

- Subjects under ASA classification 3 or greater.

- Subjects with known history of hypertrophic scar.

- Subjects allergic to acrylic.

- Subjects with medical conditions affecting the wound healing like diabetes and immunocompromised conditions.

- Lack of informed consent.

- Grossly contaminated wound.

\section{Clinical protocol}

\section{Armamentarium}

- Disposable syringes with needle

- Adson's tissue holding forceps

- Gauze

- Needle holder

- Suture cutting scissor

- Cyanoacrylate (ENDOCRYL)

- Prolene 
- Local anesthetic

\section{Methodology}

Patients requiring closure of the skin wounds of the head and neck region were selected for the study. Patients meeting all eligibility requirements were randomized for treatment with either a local application of octyl-2-cyanoacrylate or standard wound closure with polypropylene. Lacerations with the length ranging from 0.5 to $10 \mathrm{~cm}$ were included. In all cases that involved the subcutaneous tissue two layered closure was done with sutures 3-0 Vicryl and 4-0 prolene. Wounds that require surgical toilet were addressed with the debridement using hydrogen peroxide followed by cleansing of the wound with povidone iodine and saline before the closure procedure. In Group 1 the lacerations were closed with polypropylene cutting body by simple interrupted suturing technique making sure that the wound edges were in close approximation to each other during the closure. The sutures were removed after an interval of 7 days.
In Group 2 subjects were tested for acrylic allergy through intradermal patch test and were taken up for further procedure only if the test was negative. Wound edges were approximated and maintained in this position either with Adson forceps or manually with fingers. An ampule of $0.5 \mathrm{ml}$ Cyanoacrylate was broken and solution was loaded in a $2 \mathrm{ml}$ syringe, gently liquid was expressed through the needle and adhesive was applied in a thin layer along the edges of the incision. Three repeated applications with an interval of fifteen seconds were required to achieve maximum tensile strength across the wound edges. Application of any sort of medication or associated dressing was not required since the adhesive being waterproof, bacteriostatic and hemostatic acts as a protective dressing. It took as long as 5 minutes for the cyanoacrylate polymer to dry completely. Post operatively wounds were evaluated on the immediate post-operative, $7^{\text {th }}$ and $24^{\text {th }}$ postoperative days for infection, dehiscence, pain, inflammation and esthetic outcome (Figures 1\&2).

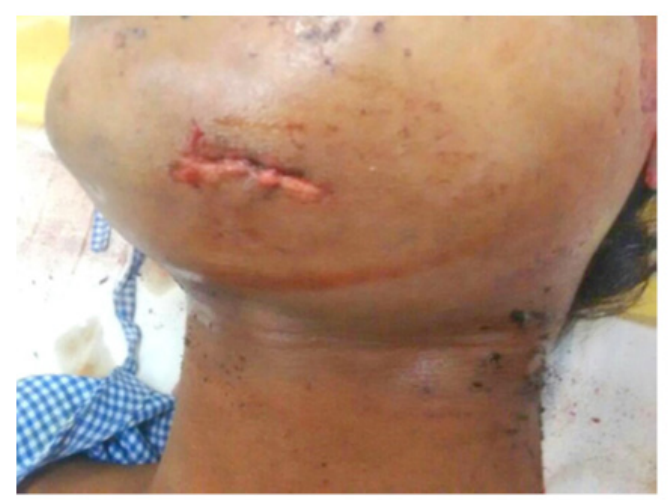

Figure 1: Group I (Polypropylene Group) Pre-operative.

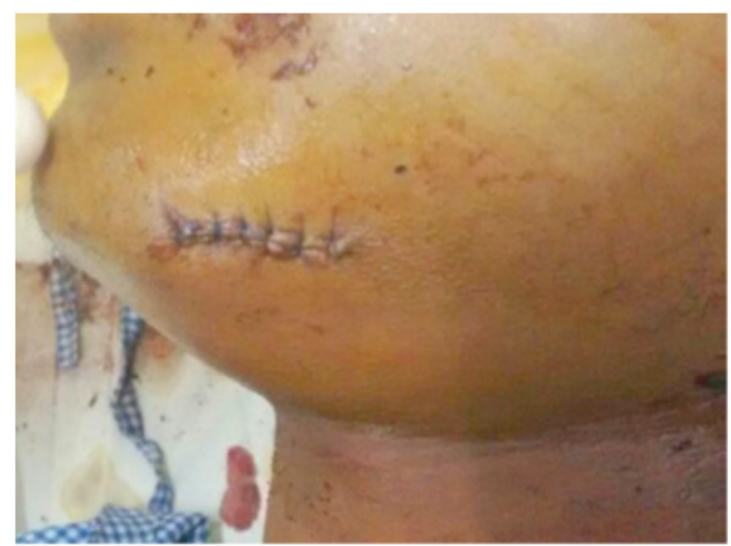

Figure 2: Immediate Post-operative.

Pain was evaluated by using a visual analog scale ranging from 0 to $10(0)$ being no pain and (10) being worst pain possible. The pain was assessed by the patient in the immediate post-operative period. Time taken was assessed in both the procedures individually from the start of the procedure to the completion of wound closure. The time taken was noted by the operator. The esthetic outcome was assessed using a previously validated 6-point scale. Lacerations were assigned 0 or 1 point each for the presence or absence of the 
following: a step-off of borders; contour irregularities; excessive wound distortion; wound margin separation; wound edge inversion and overall appearance. A total cosmetic score was then calculated by adding the individual scores for the 6 categories. Wounds with a score of 6 was considered to have an optimal cosmetic appearance.
All other wounds were considered to have a suboptimal appearance. Pain was evaluated by using a 9-point visual analogue scale (VAS) anchored by the verbal descriptors "no pain" (0) and "very severe pain" (8) (Figures 3-5).
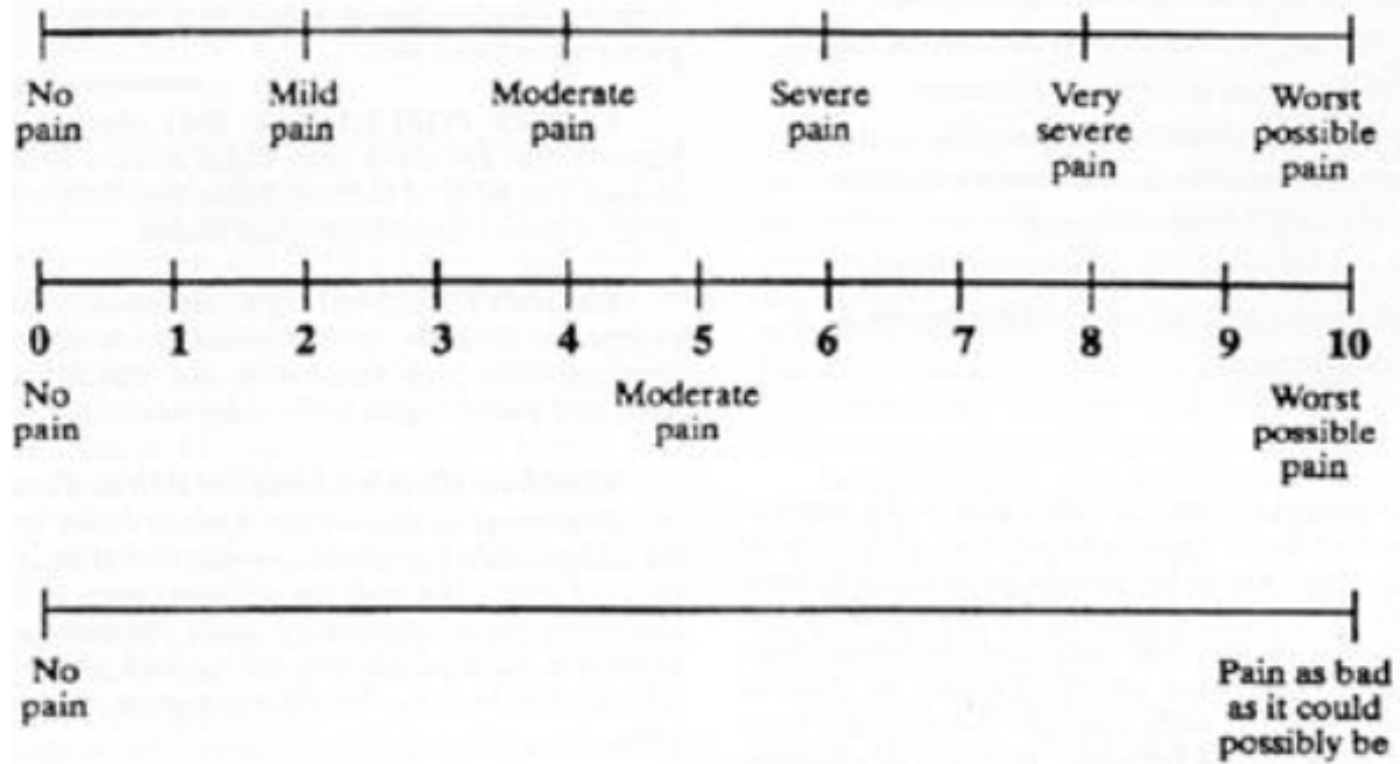

Figure 3

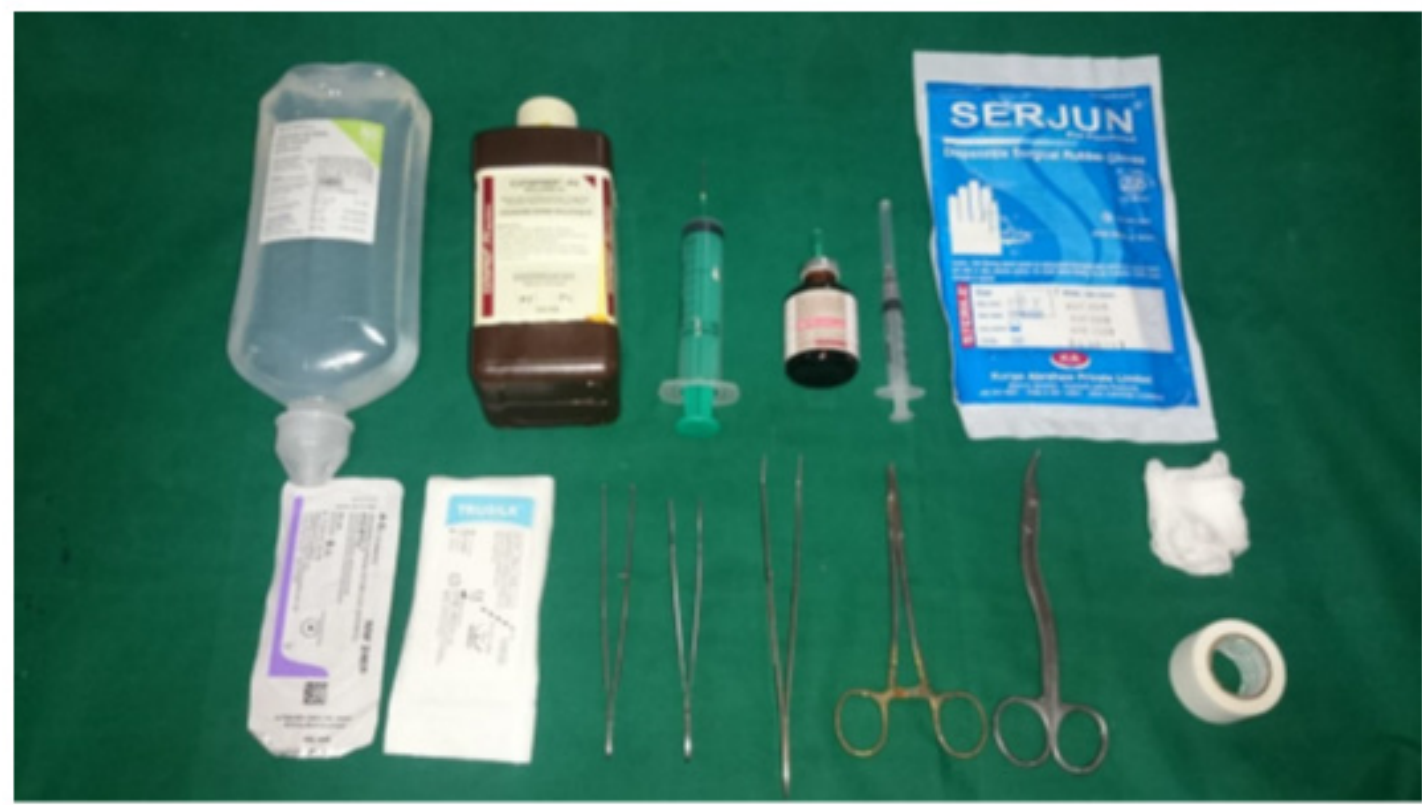

Figure 4: Armamentarium (Group 1).

\section{Results}

A total of 50 patients were included in the study. Twentyfive patients were included in suture group (group I) and 25 in cyanoacrylate group (group II). The age of patients in the suture group ranged from 17 to 50 years (mean age-32.33 years) with 23 males and 2 females. The age in the cyanoacrylate group ranged from 15 to 45 years (mean age-33 years) with 22 males and 3 females (Table 1). The patients were evaluated for wound healing complications on days 7 and 24 post-operatively (Figures 6\&7). 


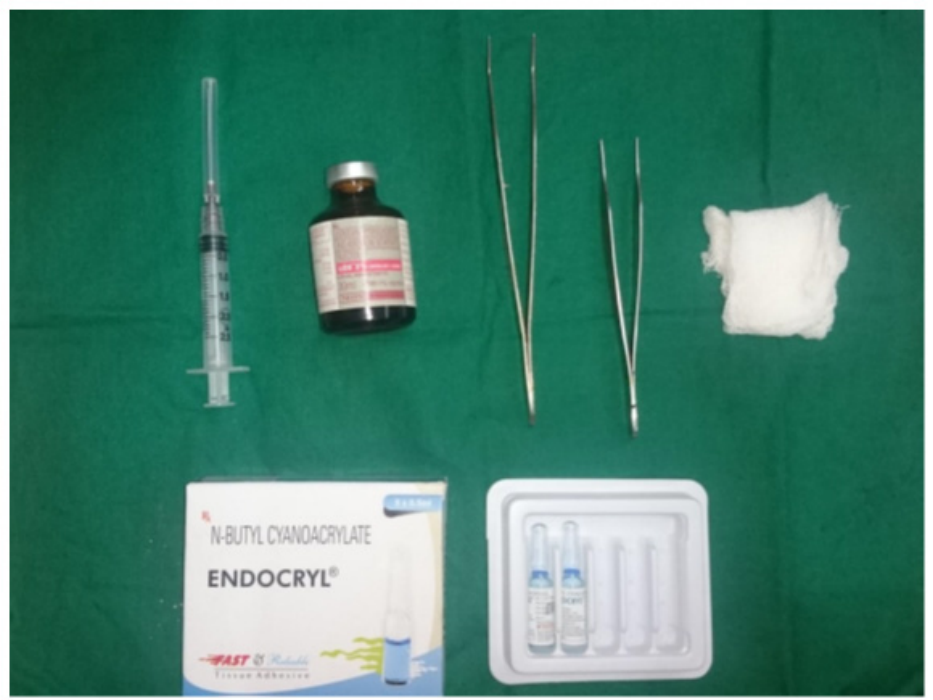

Figure 5: Armamentarium (Group 2).

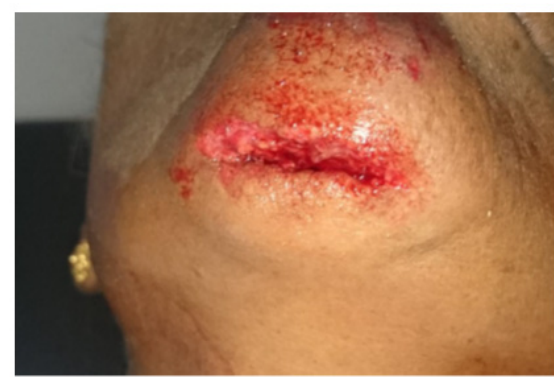

Figure 6: Group II (Cyanoacrylate) Pre-operative.

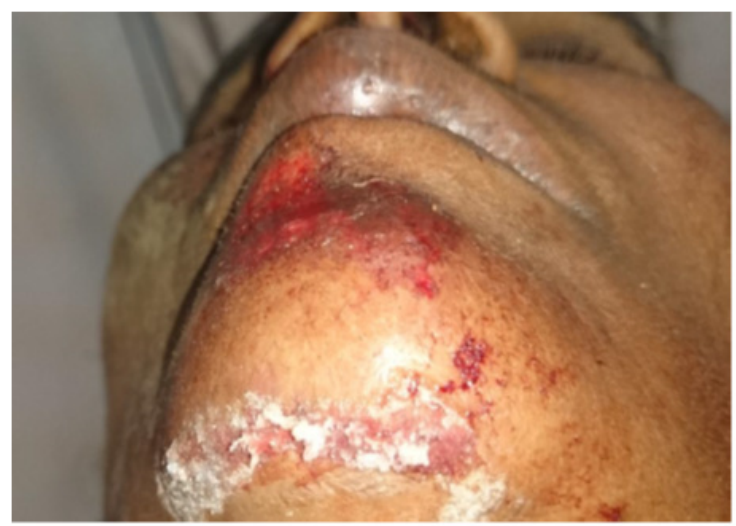

Figure 7: Immediate Post-operative.

Table 1

\begin{tabular}{|c|c|c|c|c|}
\hline \multicolumn{5}{|c|}{ Baseline Characteristics of Study Participants } \\
\hline \multirow{2}{*}{ Variable } & \multirow{2}{*}{ Categories } & PP Group & CA Group & N=25 \\
\cline { 2 - 4 } & & $\mathbf{N}=\mathbf{2 5}$ & $22(88)$ & P-value \\
\hline \multirow{2}{*}{ Gender } & Males n (\%) & $23(92)$ & $3(12)$ & \multirow{2}{*}{0} \\
\cline { 2 - 5 } & Females n (\%) & $2(8)$ & $2806 \pm 7.0$ & 0.27 \\
\hline Age & {$[$ Mean \pm SD] } & $31.2 \pm 9.2$ & & \\
\hline
\end{tabular}

Abbreviations: PP (Polypropylene), CA(Cyanoacrylate), Chi-Square Test for Gender wise Comparison, Student unpaired t test for Age wise Comparison. 


\section{Pain}

Pain was assessed by the patient in the immediate postoperative period. It was evaluated by using a visual analog scale ranging from 0 to 10,0 being no pain and 10 being worst pain possible. In the suture group pain score ranged from 3 to 8 (mean4.4). In the cyanoacrylate group, pain score ranged from 0 to 3 (mean -1.1) (Table 2) (Graph 1).

Table 2

\begin{tabular}{|c|c|c|c|c|c|c|c|c|c|c|}
\hline \multicolumn{11}{|c|}{ Comparison of pain in terms of mean VAS score among the 2 study groups using Student Unpaired $t$ test } \\
\hline \multirow{2}{*}{ Group } & \multirow{2}{*}{$\mathbf{N}$} & \multirow{2}{*}{ Mean } & \multirow{2}{*}{ SD } & \multirow{2}{*}{ S.E.M } & \multirow{2}{*}{ Mean Diff } & \multicolumn{2}{|c|}{$95 \%$ CI of the Diff } & \multirow{2}{*}{$\mathbf{t}$} & \multirow{2}{*}{ df } & \multirow{2}{*}{ P-Value } \\
\hline & & & & & & Lower & Upper & & & \\
\hline Polypropylene Group & 25 & 4.3 & 1.1 & 0.2 & \multirow[b]{2}{*}{3.2} & \multirow[b]{2}{*}{2.7} & \multirow[b]{2}{*}{3.8} & \multirow[b]{2}{*}{11.083} & \multirow[b]{2}{*}{48} & \multirow[b]{2}{*}{$<0.001^{*}$} \\
\hline Cyanoacrylate Group & 25 & 1.1 & 1 & 0.2 & & & & & & \\
\hline
\end{tabular}

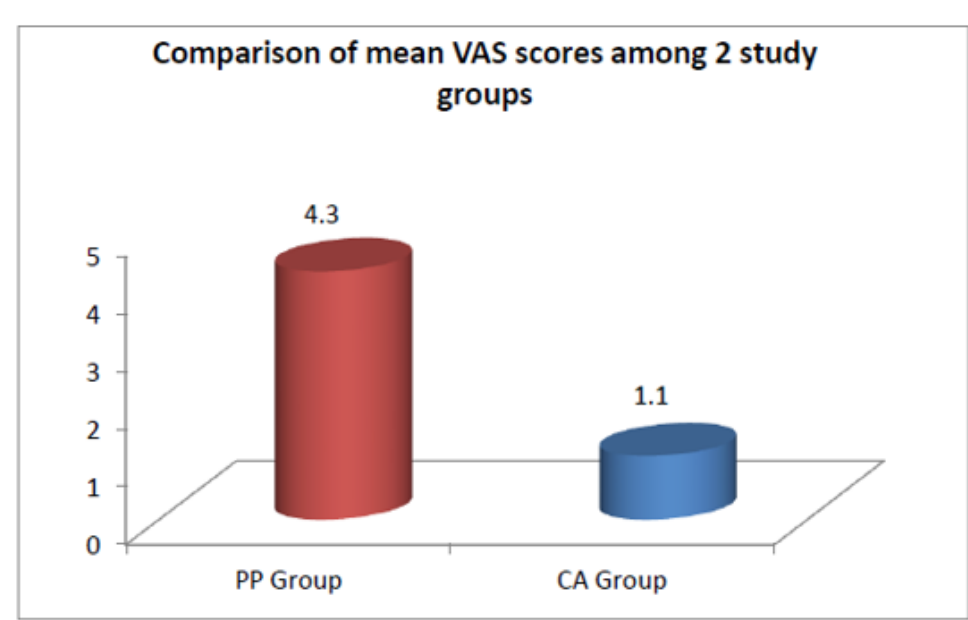

Graph 1

\section{Time taken}

Time taken was assessed in both the procedures individually from the start of the procedure to the completion of wound closure. The time taken was noted by the operator. In the suture group the time taken ranged from 15 minutes (900secs) to 60 minutes (3600secs) mean (38.1mins), similarly the time taken for the cyanoacrylate group ranged from 5 secs to 180 secs mean $(26.6$ secs) (Table 3) (Graph 2).

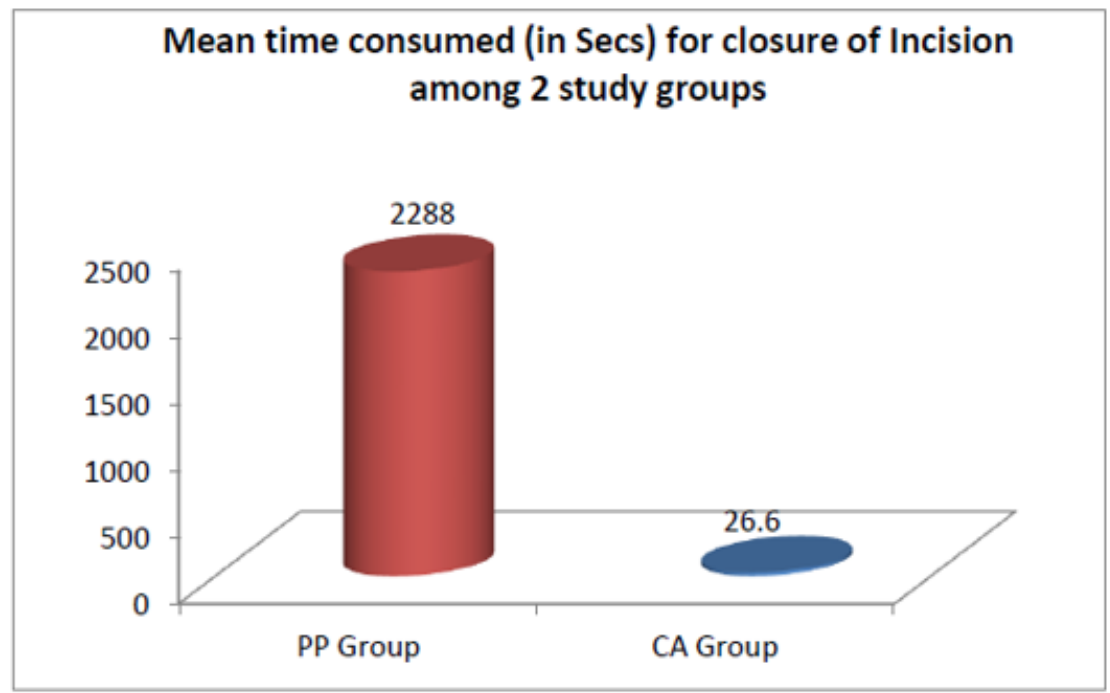

Graph 2 


\section{Table 3}

\begin{tabular}{|c|c|c|c|c|c|c|c|c|c|c|}
\hline \multicolumn{11}{|c|}{ Comparison of Mean Time taken (in sec) to close the Incision among the 2 study groups using Student Unpaired t Test } \\
\hline \multirow{2}{*}{ Group } & \multirow{2}{*}{$\mathbf{N}$} & \multirow{2}{*}{ Mean } & \multirow{2}{*}{ SD } & \multirow{2}{*}{ S.E.M } & \multirow{2}{*}{ Mean Diff } & \multicolumn{2}{|c|}{ 95\% CI of the Diff } & \multirow{2}{*}{$\mathbf{t}$} & \multirow{2}{*}{ df } & \multirow{2}{*}{ P-Value } \\
\hline & & & & & & Lower & Upper & & & \\
\hline Polypropylene Group & 25 & 2288 & 873.8 & 174.8 & \multirow{2}{*}{2261.4} & \multirow{2}{*}{1909.6} & \multirow{2}{*}{2613.1} & \multirow{2}{*}{12.926} & \multirow{2}{*}{48} & \multirow{2}{*}{$<0.001^{*}$} \\
\hline Cyanoacrylate Group & 25 & 26.6 & 39.8 & 8.0 & & & & & & \\
\hline
\end{tabular}

\section{Infection}

Six patients (24\%) of the suture group presented with infection of the wound on the $7^{\text {th }}$ day of evaluation. Two patients $(8 \%)$ of

Table 4

\begin{tabular}{|c|c|c|c|c|}
\hline \multicolumn{5}{|c|}{ Comparison of Post-operative infection on $7^{\text {th }}$ Day among 2 study groups using Chi Square test } \\
\hline Post-OP Infection & PP Group & CA Group & Chi-Square Value & P-Value \\
\hline \multirow{2}{*}{ Absent } & 19 & 23 & \multirow{4}{*}{2.381} & \multirow{4}{*}{0.24} \\
\hline & $76 \%$ & $92 \%$ & & \\
\hline \multirow{2}{*}{ Present } & 6 & 2 & & \\
\hline & $24 \%$ & $8 \%$ & & \\
\hline
\end{tabular}

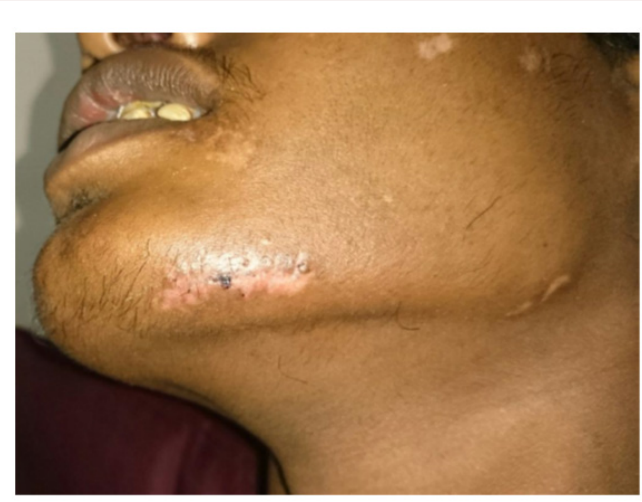

Figure 8: Post OP $7^{\text {th }}$ Day.

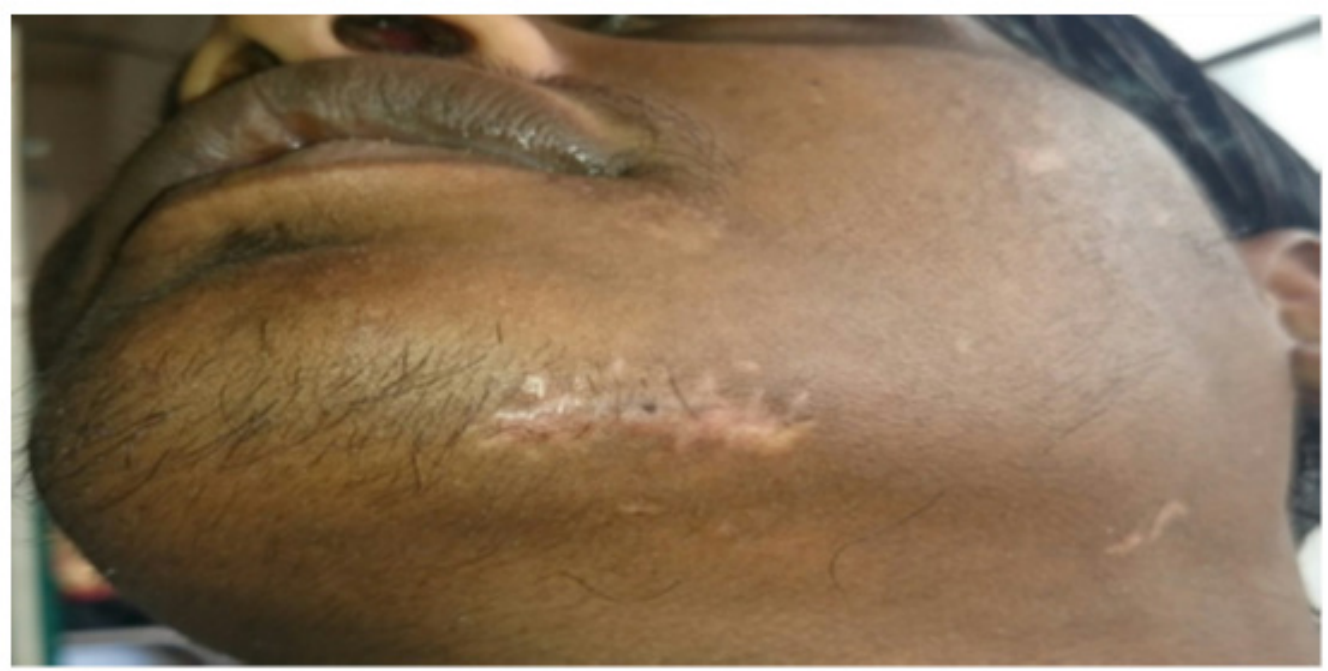

Figure 9: Post OP 24 $4^{\text {th }}$ Day. 


\section{Inflammation}

On the 7th post-operative day, in the polypropylene suture group, 14 patients (56\%) and in the cyanoacrylate group, 17 patients (68\%) showed no signs of inflammation. 8 patients (32\%) and 4 patients (16\%) from the suture group and cyanoacrylate group respectively had mild inflammation. 2 patients $(8 \%)$ and 1 patient (4\%) in the polypropylene suture group showed moderate and severe inflammation respectively. Similarly, in the cyanoacrylate group, 4 patients $(16 \%)$ had moderate inflammation of the wound and none of them showed severe inflammation. Evaluation of the wound on the $24^{\text {th }}$ day showed no signs of inflammation in both the groups (Table 5) (Graph 4).

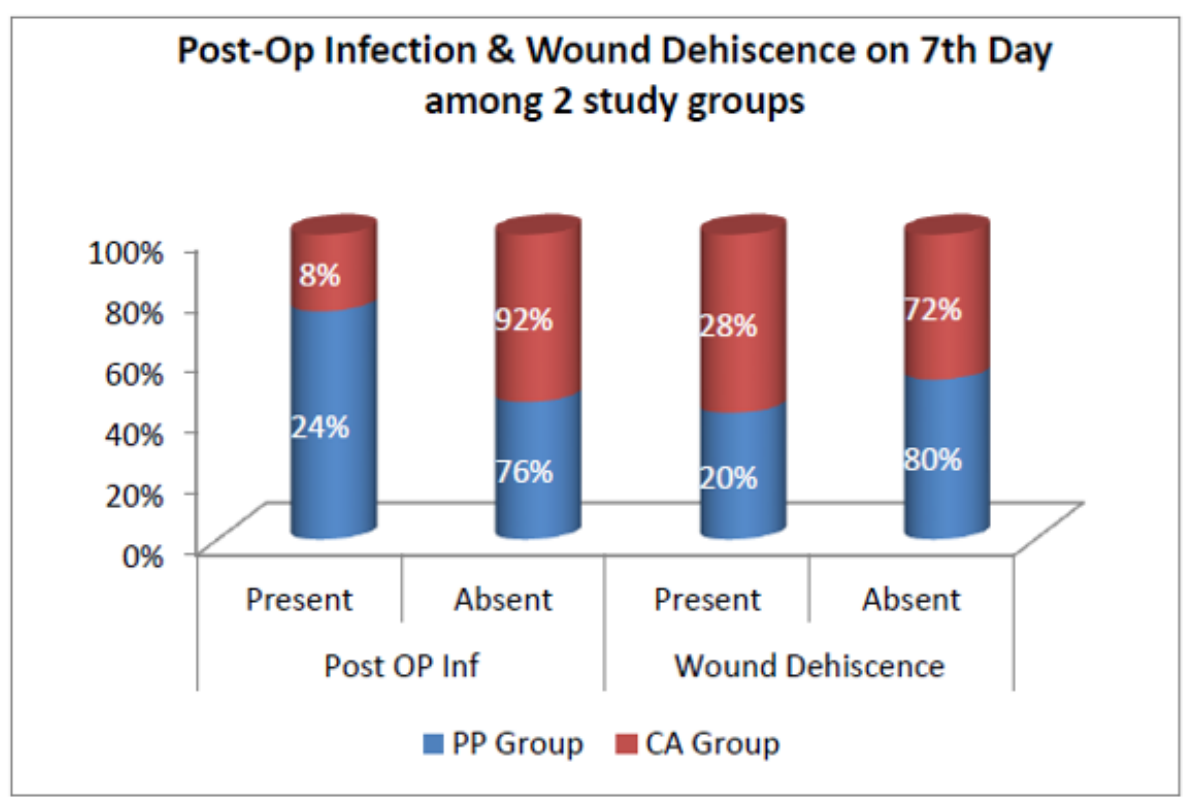

Graph 3

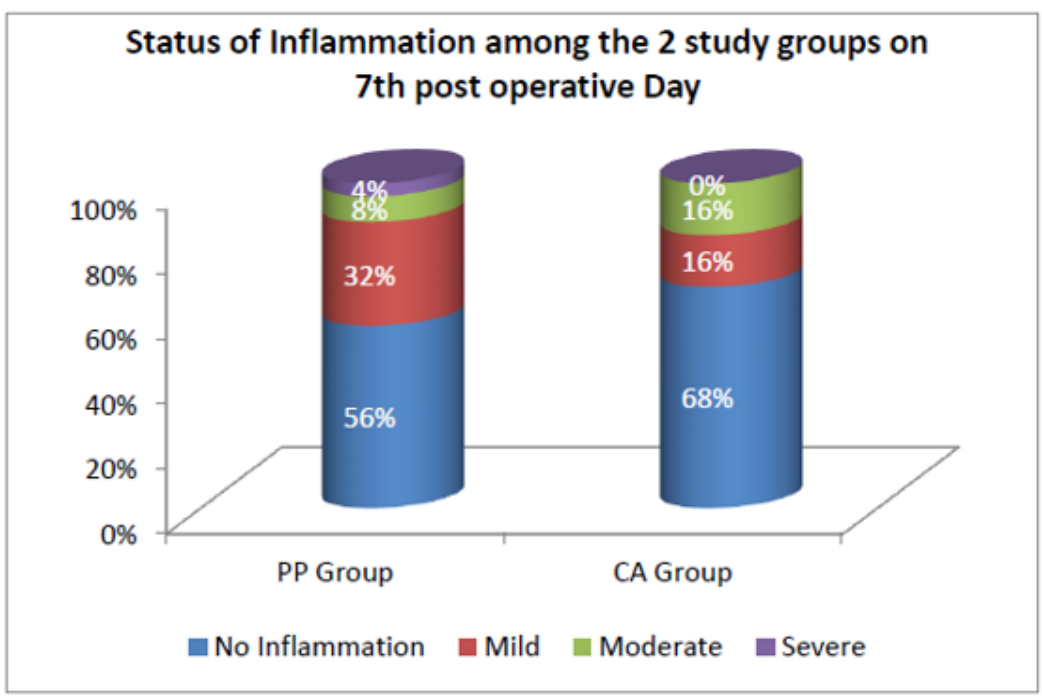

Graph 4

\section{Wound dehiscence}

Five patients $(20 \%)$ of polypropylene suture group exhibited wound dehiscence on day 7 . Seven patients (28\%) of cyanoacrylate group exhibited wound dehiscence on the seventh post-operative day. No patient exhibited dehiscence on the $24^{\text {th }}$ post-operative day from both the groups (Table 6) (Graph 3). Sutures were usually removed after 5 to 7 days post-operatively, whereas the cyanoacrylate was allowed to peel off by itself. It was noted that, in 21 patients $(84 \%)$ the adhesive peeled off by $7^{\text {th }}$ day, whereas it remained for longer time in the remaining 4 patients (16\%). 
Table 5

\begin{tabular}{|c|c|c|c|c|}
\hline \multicolumn{5}{|c|}{ Comparsion of Inflammation on $7^{\text {th }}$ Day among 2 study groups using Chi Square test } \\
\hline \multirow{2}{*}{ Information } & \multicolumn{2}{|c|}{ Group } & \multirow{2}{*}{ Chi-Square Value } & \multirow{2}{*}{ P-Value } \\
\hline & PP Group & CA Group & & \\
\hline \multirow{2}{*}{ No Information } & 14 & 17 & \multirow{8}{*}{3.29} & \multirow{8}{*}{0.35} \\
\hline & $56 \%$ & $68 \%$ & & \\
\hline \multirow{2}{*}{ Mild } & 8 & 4 & & \\
\hline & $32 \%$ & $16 \%$ & & \\
\hline \multirow[b]{2}{*}{ Moderate } & 2 & 4 & & \\
\hline & $8 \%$ & $16 \%$ & & \\
\hline \multirow[b]{2}{*}{ Severe } & 1 & 0 & & \\
\hline & $4 \%$ & $0 \%$ & & \\
\hline
\end{tabular}

Table 6

\begin{tabular}{|c|c|c|c|c|}
\hline Comparsio & cence on 7 & 2 study gro & sing Chi Square tes & \\
\hline \multirow{2}{*}{ Post-OP Wound dehisecence } & \multicolumn{2}{|c|}{ Group } & \multirow{2}{*}{ Chi-Square Value } & \multirow{2}{*}{ P-Value } \\
\hline & PP group & CA Group & & \\
\hline \multirow{2}{*}{ Absent } & 20 & 18 & \multirow{4}{*}{0.439} & \multirow{4}{*}{0.74} \\
\hline & $80 \%$ & $72 \%$ & & \\
\hline \multirow{2}{*}{ Present } & 5 & 7 & & \\
\hline & $20 \%$ & $28 \%$ & & \\
\hline
\end{tabular}

\section{Esthetic outcome}

Esthetic outcome was assessed using a previously validated 6-point scale. Lacerations were assigned 0 or 1 point each for the presence or absence of the following: a step-off of borders, contour irregularities, excessive wound distortion, wound margin separation, wound edge inversion and overall appearance. A total cosmetic score was then calculated by adding the individual scores for the 6 categories. Wounds with a score of 6 were considered to have an optimal cosmetic appearance; all other wounds were considered to have a suboptimal appearance.
The overall appearance score of the wound in the polypropylene suture group ranged from 2 to 4 (mean- 3.2) and in the cyanoacrylate group the scores ranged from 3 to 4 (mean3.8 ) on the immediate post-operative evaluation. On the $7^{\text {th }}$ day evaluation, the score of the suture group ranged from 0 to 4 (mean 2.76) and that of the cyanoacrylate ranged from 1-4 (mean 2.88). On the $24^{\text {th }}$ post-operative day, the scores of both the suture group and the cyanoacrylate group ranged from 1-4 (mean 3.12) (Tables 7-9) (Graph 5) (Figures 10\&11).

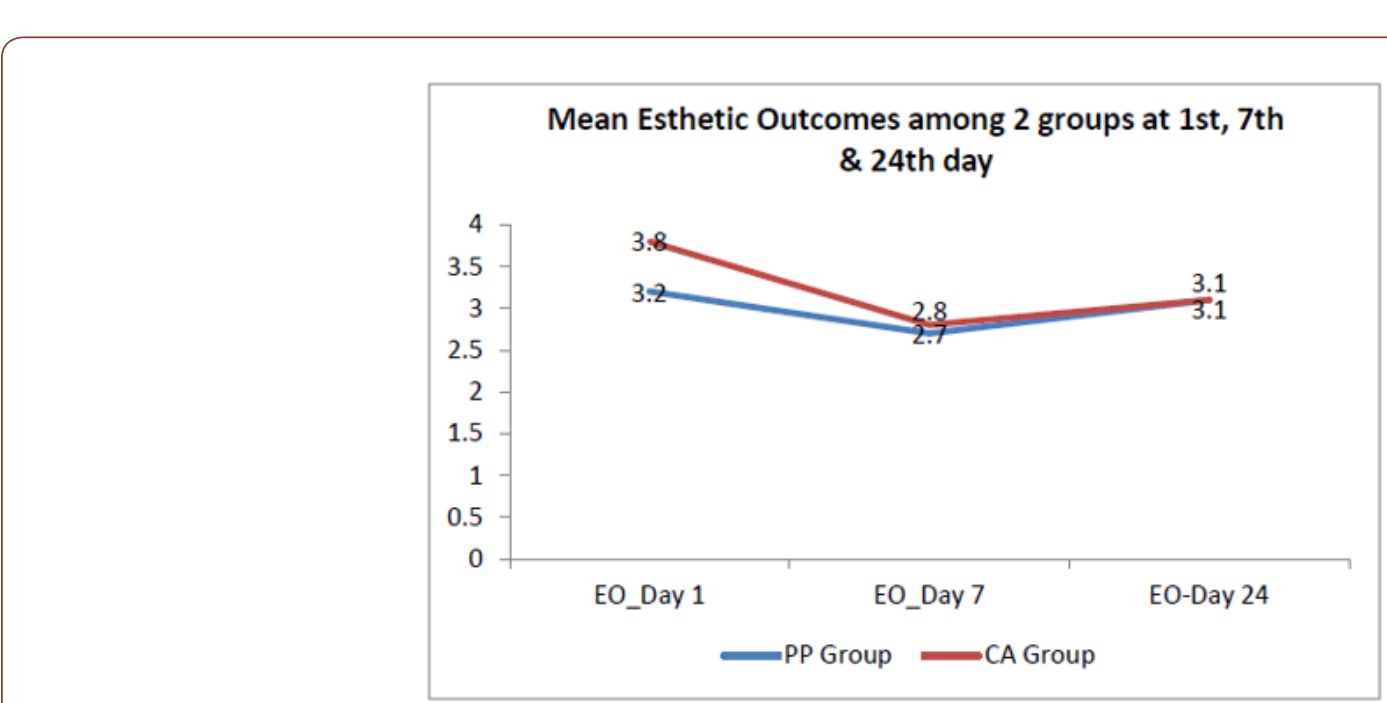

Graph 5 


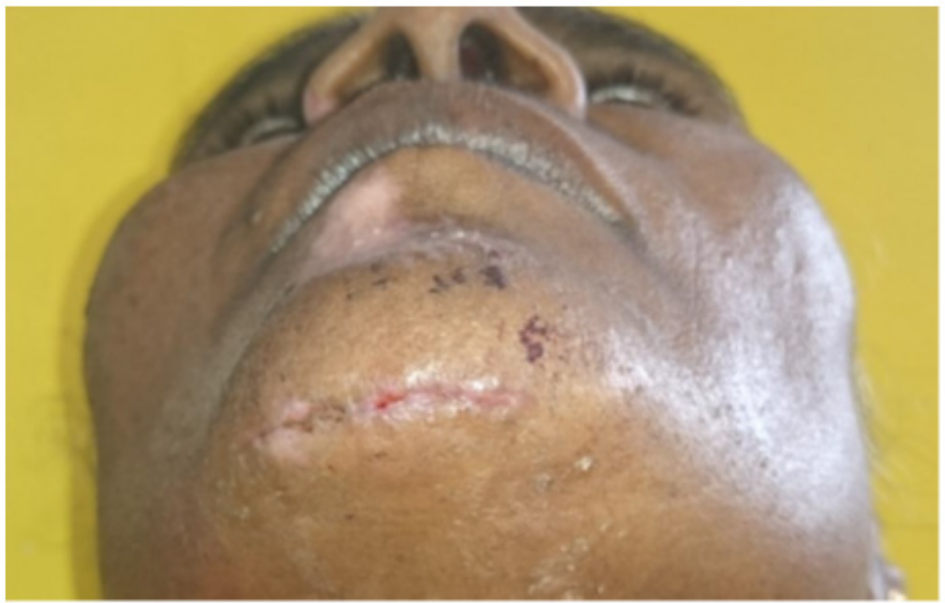

Figure 10: Post OP $7^{\text {th }}$ Day.

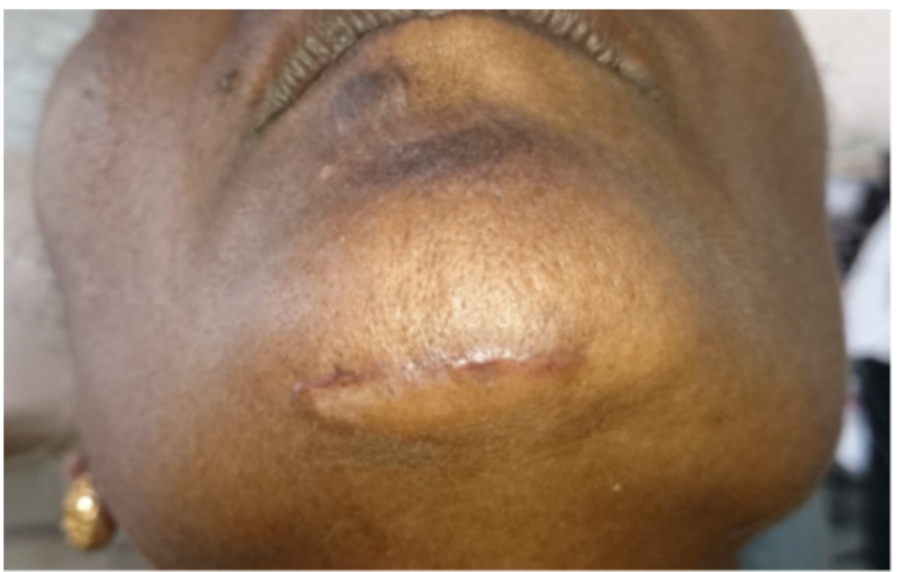

Figure 11: Post of $24^{\text {th }}$ Day

Table 7

Comparison of Mean Esthetic Outcome on Day 1 among the 2 study groups using Student Unpaired t test

\begin{tabular}{|c|c|c|c|c|c|c|c|c|c|c|}
\hline \multirow{2}{*}{ Group } & \multirow{2}{*}{$\mathbf{N}$} & \multirow{2}{*}{ Mean } & \multirow{2}{*}{ SD } & \multirow{2}{*}{ S.E.M } & \multirow{2}{*}{ Mean Diff } & \multicolumn{2}{|c|}{$95 \%$ CI of the Diff } & \multirow{2}{*}{$\mathbf{t}$} & \multirow{2}{*}{ df } & \multirow{2}{*}{ P-Value } \\
\hline & & & & & & Lower & Upper & & & \\
\hline Polypropylene Group & 25 & 3.2 & 0.7 & 0.1 & \multirow{2}{*}{-0.60} & \multirow{2}{*}{-0.92} & \multirow{2}{*}{-0.27} & \multirow{2}{*}{-0.3674} & \multirow{2}{*}{48} & \multirow{2}{*}{$0.001^{*}$} \\
\hline Cyanoacrylate Group & 25 & 3.8 & 0.4 & 0.1 & & & & & & \\
\hline
\end{tabular}

Table 8

Comparison of Mean Esthetic Outcome on Day 7 among the 2 study groups using Student Unpaired t test

\begin{tabular}{|c|c|c|c|c|c|c|c|c|c|c|}
\hline \multirow{2}{*}{ Group } & \multirow{2}{*}{$\mathbf{N}$} & \multirow{2}{*}{ Mean } & \multirow{2}{*}{ SD } & \multirow{2}{*}{ S.E.M } & \multirow{2}{*}{ Mean Diff } & \multicolumn{2}{|c|}{ 95\% CI of the Diff } & \multirow{2}{*}{$\mathbf{t}$} & \multirow{2}{*}{ df } & \multirow{2}{*}{ P-Value } \\
\hline & & & & & & Lower & Upper & & & \\
\hline Polypropylene Group & 25 & 2.76 & 1.2 & 0.2 & \multirow{2}{*}{-0.12} & \multirow{2}{*}{-0.78} & \multirow{2}{*}{0.54} & \multirow{2}{*}{-0.364} & \multirow{2}{*}{48} & \multirow{2}{*}{0.72} \\
\hline Cyanoacrylate Group & 25 & 2.86 & 1.1 & 0.2 & & & & & & \\
\hline
\end{tabular}

Table 9

Comparison of Mean Esthetic Outcome on Day 24 among the 2 study groups using Student Unpaired t test

\begin{tabular}{|c|c|c|c|c|c|c|c|c|c|c|}
\hline \multirow{2}{*}{ Group } & \multirow{2}{*}{$\mathbf{N}$} & \multirow{2}{*}{ Mean } & \multirow{2}{*}{ SD } & \multirow{2}{*}{ S.E.M } & \multirow{2}{*}{ Mean Diff } & \multicolumn{2}{|c|}{$95 \%$ CI of the Diff } & \multirow{2}{*}{$\mathbf{t}$} & \multirow{2}{*}{ df } & \multirow{2}{*}{ P-Value } \\
\hline & & & & & & Lower & Upper & & & \\
\hline Polypropylene Group & 25 & 3.12 & 0.9 & 0.2 & \multirow{2}{*}{0.00} & \multirow{2}{*}{-0.47} & \multirow{2}{*}{0.47} & \multirow{2}{*}{0} & \multirow{2}{*}{48} & \multirow{2}{*}{1.00} \\
\hline Cyanoacrylate Group & 25 & 3.12 & 0.9 & 0.2 & & & & & & \\
\hline
\end{tabular}




\section{Discussion}

The present study was carried out to evaluate the clinical outcome of lacerations when closed with sutures and cyanoacrylate. The efficacy of cyanoacrylate as an adhesive in the skin closure as compared to the conventional suture technique. The goals of wound management are simple: avoid infection and achieve a functional and aesthetically pleasing scar. These goals may be achieved by reducing tissue contamination, debriding devitalized tissue, restoring perfusion in poorly perfused wounds, and establishing a well approximated skin closure [1]. Nonabsorbable sutures, such as nylon and polypropylene, retain most of their tensile strength for longer than 60 days, are relatively nonreactive, and are appropriate for closure of the outermost layer of the laceration. Removal of nonabsorbable sutures is required [1].

Absorbable sutures are usually used for closure of structures deeper than the epidermis. In general, synthetic absorbable sutures are less reactive and have greater tensile strength than sutures from natural sources, such as catgut. They increase the time during which the healing wound retains $50 \%$ of its tensile strength from less than 1 week to as long as 2 months. Deep sutures help relieve skin tension, decrease dead space and hematoma formation, and probably improve cosmetic outcome. Synthetic and monofilament sutures are preferred over natural and braided sutures because they result in lower rates of infection [1]. The conventional technique for wound closure with sutures may cause disturbance of healing process by stitch infection, foreign body reaction, increased inflammatory reaction and interference to circulation within the wound. Wound infection has been shown to be more in suture technique. Sutures provide an extra source of contamination via suture canal, peri sutural cuff of dead epidermis, dermis and subcutaneous fat.

It provides all the factors necessary to initiate infection in following ways: by

1) providing route of entry from skin to subcutaneous tissue,

2) providing route of entry from intradermal structures, hair follicles, sebaceous glands etc.

3) maintaining patency of tract for 5-10 days,

4) causing foreign body reaction with associated local tissue autolysis, so that sutures can break down the tissue barrier into more infected intradermal structures (e.g., sebaceous gland) which were not open at the time of initial passage of suture and

5) due to foreign body reaction and local tissue autolysis, likelihood of suture to be bathed in liquified protein which will both proliferate and increase the activity of bacteria.

Carpendale and Sereda, in their studies, showed that tapes working on the same principle as cyanoacrylate. They tied sutures to non-incised skin and showed $10.8 \%$ infection rate [5]
Adhesive strips such as steristrips represent the other "no needle" alternative to sutures. They are an acceptable method of closure of lacerations that are small and under low tension. They are disadvantageous as they peel off from skin when wetted. They cannot be used over the joints and on hairy skin. In a unique randomized controlled trial that compared steristrips with cyanoacrylates adhesive, it was noted that no significant difference was found in cosmetic outcome or complication rates [6]. Cyanoacrylates were first synthesized in 1949 and were first used in surgery 10 years later when Coover discovered their inherent adhesive properties. Extensive descriptive and comparative studies have been conducted to confirm their role as a favorable option in closing superficial wounds. In contrast to fibrin tissue adhesives, which rely on the interaction of endogenous compounds, the cyanoacrylate tissue adhesives are synthetic compounds that do not naturally occur in the human body [4].

However, a study by Leonard in 1968 demonstrated that methyl 2-cyanoacrylate elicited acute inflammatory reactions when used on tissues and thus had histotoxicity though it produced good bonding. The cause of this histotoxicity was rapid degradation of short chain derivatives into formaldehyde and cyanoacetate which were not excreted at sufficient rate and accumulated locally in tissues and thus causing inflammation [7]. Sutures essentially have to be left in situ for 5 to 10 days. If prematurely removed the tensile strength of wound may not be adequate to provide support to tissue edges. This can result in wound dehiscence and eventual widening of resultant scar. Conversely, if sutures are left behind too long or placed tightly, the risk of permanent suture tracks increases [7]. The use of cyanoacrylates eliminates this problem. However, studies have shown that the wound breaking strength is equal to that of suture repaired wounds at 5 to 7 days, but the day 1 wound breaking strength is only about $10-15 \%$ that of wound closed with 5-0 monofilament sutures. This restricts the use of adhesive to the areas of low tension and with minimal movement [8].

Furthermore, the length and the depth of laceration or wound limit the use of cyanoacrylates. Cyanoacrylates are helpful in partial thickness wounds and smaller laceration due to their less bond strength and histotoxicity. Additional factors involving tissue adhesives are the antimicrobial effect of adhesive, Langer's lines, wound reactions and potential carcinogenicity and financial aspect [6]. Biodegraded products from the adhesives evoke a histotoxic effect within the tissues which would be self-limiting and resolve on its own. Cyanoacrylate adhesives have been shown to be toxic invitro, it is possible that only commercial cyanoacrylate adhesives release cytotoxic substances for a prolonged period. It can be toxic to the neurological system, as well as causing contact dermatitis and urticaria [9].

The temperature rise of 1.5 degrees to 4 degrees has been noted to occur as the polymerization reaction progresses. This heat that is dissipated during polymerization can cause tissue damage. This 
can manifest clinically as a burning sensation at the surgical site. It is thus recommended that the adhesive should always be used in small quantities and has to be applied in layers at the site so as to prevent heat buildup within the tissues. Another complication that can arise due to seepage of adhesive into deeper layers is delayed healing as the adhesive forms a barrier and prevents epithelialization of wound edges [10]. The cyanoacrylate adhesives being synthetic resins, bind the tissue edges together with a chemical bond. This bond though strong, is brittle and less flexible in case of short chain compounds. The newer formulations (long chain derivatives) are a combination of monomers and plasticizers. This produces a strong flexible bond which has a 3-dimensional breaking strength 4 times that of shorter chain compounds. This is true of octyl 2-cyanoacrylate when compared with n-butyl 2-cyanoacrylate. However, other factors like the length of wound also play an important role. The longer the incision greater are the chances of failure of adhesive [10].

In vitro studies that compared Isoamyl 2-cyanoacrylate with n-butyl cyanoacrylate in terms of bond strengths concluded that IsoAmyl 2-cyanoacrylate had lower bond strength (2.36MPa3.03MPa) than n-butyl cyanoacrylate (4.77MPa-6.02MPa). Failure occurred with n-butyl cyanoacrylate due to bond failure at adhesive substrate interface whereas with IsoAmyl 2-cyanoacrylate group failure was within the material itself [7]. In our study, Prolene (polypropylene) was used for suturing the wounds. Prolene being a monofilament suture material does not have the disadvantages of multifilament sutures. A Randomized prospective study by Sahu, et al. [11] Compared the efficacy between N-butyl cyanoacrylate tissue adhesive and Ethilon nylon sutures in extraoral maxillofacial incisions and concluded that Wound infection, dehiscence, necrosis of tissue edges, time taken for closure was much less in case of tissue adhesive than conventional sutures [12].

Cyanoacrylate has shown to demonstrate antibacterial effects on Bacillus subtilis [11]. They have also shown to reduce the counts of Staphylococcus aureus which is a common pathogen present over skin surface. These can thus be used even in clean contaminated and contaminated wounds. The adhesive acts as a dressing by itself by creating a resinous barrier between wound surface and the external environment thus reducing wound contamination. The cyanoacrylates decrease the closure time, have a good cosmetic outcome, require no dressings, have antibacterial properties, require no removal and have a very good patient acceptability. In our study we found that cyanoacrylate performs as well as standard wound closure techniques in terms of wound infection rates, wound dehiscence and long-term cosmetic outcome. We also found that patients who received wound closure with cyanoacrylate were less likely to require anesthesia, did not require the surgeon to wait for the onset of anesthesia prior to closing the wound, and had significantly faster wound closure times. Additionally, use of cyanoacrylate eliminated the need for suture removal.
We also found that the pain associated with closure of wounds with cyanoacrylate was significantly lesser than the suturing. In addition, infection and inflammation rates with cyanoacrylate was comparatively less as they have bacteriostatic properties. In contrast we observed that wound dehiscence was more predominant in the cyanoacrylate group. We found no clinically important cosmetic differences in facial wounds that were closed by polypropylene sutures and cyanoacrylate.

\section{Conclusion}

In our study we experienced the use of N-Butyl-2-cyanoacrylate. We noted that it is an easily applied material, has good physical properties, has good wound healing characteristics, overcomes the disadvantage and discomfort of suture removal, infection, duration of closure and produces cosmesis comparable to that produced by sutures with excellent patient satisfaction. With a limited number of samples and study, we hereby conclude that with a proper patient selection, meticulous technique and limitation to external use, Cyanoacrylate can serve as a good and reliable alternative to sutures for lacerated wounds in the minimal tension areas of the face.

\section{Acknowledgement}

None.

\section{Funding}

No funding.

\section{Conflict of Interest}

The authors have no conflict of interest to declare.

\section{Ethical Approval}

The current research was approved by ethics committee of Vydehi Institute of Dental Sciences and Research Centre.

\section{References}

1. Hollander JE, Singer AJ (1999) Laceration management. Ann Emerg Med 34: 356-367.

2. Nagpal BM, Kumar G, Nagi GS, Singh P (2004) Sutureless closure of operative skin wounds. MJAFI 60: 131-133.

3. Coover HW, Joyner FB, Shearer NH, Wicker TH (1959) Chemistry and performance of cyanoacrylate adhesives. J Soc Plast Surg Eng 15: 413417.

4. Mobley SR, Hilinski J, Toriumi DM (2002) Surgical tissue adhesives. Facial Plast Surg Clin N Am 10: 147-154.

5. Dalvi AA, Faria MM, Pinto AA (1986) Non-suture closure of wound using cyanoacrylate. J Postgrad Med 32: 97-100.

6. A Mattick, G Clegg, T Beattie, T Ahmad (2002) A randomised, controlled trial comparing a tissue adhesive (2-octylcyanoacrylate) with adhesive strips (Steristrips) for paediatric laceration repair. Emerg Med J 19: 405-407.

7. Gassner R (2002) Wound closure materials. Oral Maxillofacial Surg Clin N Am 14: 95-104.

8. Sortino F, Lombardo C, Sciacca A (2008) Silk and polyglycolic acid in oral surgery: A comparative study. Oral Surg Oral Med Oral Pathol Oral Radiol Endod 105: 15-18. 
9. Leggat P.A, Kedjarune U, Smith DR (2004) Toxicity of Cyanoacrylate Adhesives and Their Occupational Impacts for Dental Staff. Ind Health 42: 207-211.

10. Davis BR, Sandor GK (1998) Use of Fibrin Glue in Maxillofacial Surgery. J Otolaryngol 27(2): 107-112.

11. Sahu S, Mishra S, Lenka S, Banerjee R, Pachisia S, etal. (2019) Comparison between N-butyl cyanoacrylate tissue adhesive and Ethilon nylon sutures in extraoral maxillofacial incisions: A randomized prospective study. J Oral Biol Craniofac Res 9(3): 173-178.

12. L Montanaro, CR Arciola, E Cenni (2001) Cytotoxicity, blood compatibility and antimicrobial activity of two cyanoacrylate glues for surgical use. Biomaterials 22: 59-66. 